\title{
The Impact of Water Aerobics Program on Cardiorespiratory Fitness
}

\author{
Indah Ayu Puji Lestari*, Mustika Fitri, Kuston Sultoni \\ Sport Science Study Program, Faculty of Sport and Health Science Education, \\ Universitas Pendidikan Indonesia, \\ Bandung, Indonesia \\ *indahayupuzi@gmail.com, mustikafitri@upi.edu, kustonsultoni@upi.edu
}

\begin{abstract}
To improve health and life quality, every individual needs to do physical activity on a daily basis. One of the ways is through cardiorespiratory exercises. A type of exercise that can improve cardiorespiratory fitness is water aerobics. This kind of aerobics can be done by people of all ages and also can be an alternative for adults who dislike sports on land. This research was aimed at finding out the impact of water aerobics. 20 university students were involved as samples of this research. The samples were divided into two groups; group 1 (water aerobics) and group 2 (aerobics dance). The design implemented in this research was The Randomized Pretest-Posttest Control Group Design, with accidental sampling/convenience sampling as the technique to take the sample. The result of the data analysis showed that both water aerobics and aerobic dance had impacts on the improvement of cardiorespiratory fitness. Another result found that aerobic dance was more effective in improving cardiorespiratory fitness compared to water aerobics.
\end{abstract}

Keywords: aerobic dance, cardiorespiratory fitness, college student, water aerobic

\section{INTRODUCTION}

To improve health and life quality, every individual should do physical activity on a daily basis. Surgeon General's report in 1996 recommended Americans to at least do 30 minutes of physical activity on medium intensity for almost every day in a week to maintain the heart's health. [1]. Fact shows that physical activity increases from day to day, from school years, university years, until people graduate from university [2]. From the American population, almost half of teenagers at the age of 12-21 are not active on doing physical activity regularly. The same thing goes to adults with a percentage of $60 \%$ and $25 \%$ for adults who are not actively doing physical activity [1]. The decreasing in physical activity might cause some risk factors of illness like obesity, heart disease, diabetes type 2, and the decreasing of physiologic function as someone goes older [3]. But, the situation can be overcome by changing the lifestyle and doing physical activity with cardiorespiratory $[5,4]$.

Cardiorespiratory fitness is an ability of the blood circulation system and respiratory to produce oxygen when physical activity sustainably happens [6]. Having a good cardiorespiratory fitness is supported by doing a routine exercise, Hoeger [7] explains by doing an exercise for 6 until 8 weeks, heartbeat rest increases 10 until 20 times a minute (bpm) and that will save the heart at least 10.483 .200 beats a year. Besides that, the benefit of having a good cardiorespiratory fitness is to have an ability to recover faster after doing an activity, to increase functional capillary result, and to increase enzyme of fat burning.

Kinds of activity that can be done to improve cardiorespiratory fitness are to walk, jog, ride a bicycle, aerobics, swim, do a strength exercise, and stretching [8]. But, an interesting physical activity these days is aerobics dance where the participant can exercise while socializing and having fun [9]. Aerobics dance becomes a new trend in sports growth to increase an individual's performance [10]. A regular aerobics dance activity might improve cardio respiration fitness [11] helps an individual to control weight, and to prevent cardiovascular illness [12]. A lot of researchers have observed aerobics dance to improve VO2Max; including topics about the effects of aerobics dance towards the ability of physical activity capacity, the function of cardiovascular, and women's body composition by Dowdy [13], impacts of aerobics dance for improving women's cardiovascular and weight by Ahmad et al. [9], also the change of cardiorespiratory response and body composition by doing aerobics dance program done by Williams and Morton [14].

Besides aerobics dance, several previous researchers have improved kinds of activities that can be utilized to improve cardiorespiratory fitness and one of them is water aerobics. Water aerobics is one of the movements in the aerobics movement done in water [15]. Water aerobics can enhance flexibility without causing damage to the joints and a risk to have an injury due to the lessen gravity effect inside the water. So, joints can move easier [16]. Aerobics done in the water can be followed by people of all ages. But for adults, it also can be an alternative for those who do not like sports on the land. Some of them might avoid exercise done on the land due to lower back pain during pregnancy, according to Granath et al. [17]. Besides lower back pain, people who avoid exercise on the land are those who have a problem with their joints [18]. Aside from the facts stated beforehand, water aerobics training 
also has an important role to improve physical fitness [19] and to improve strength parameter [20].

\section{METHOD}

\section{A. Recearch Design}

This research utilized experimental design, where subjects are given treatment. As for the design, the design used in this research was the randomized pretest-posttest control group design, where the subjects did pretest to know the cardiorespiratory fitness in the first place. Then, they would be given aerobics dance and water aerobics training for 6 weeks. After that, the subjects would be given a posttest to find out about the last output of their cardiorespiratory fitness.

\section{B. Participant}

The sample involved in the research were 20 university students at the age of \pm 20 years old divided into two groups, group 1 (experiment group) and group 2 (control group). The technique applied to get the sample was accidental sampling/convenience sampling where both samples were chosen randomly then they would be given a form of agreement to be involved in the research.

\section{Instrument}

The adopted instrument in this research was by using Pacer Test [21], that is to do run back forward for 20 meters while following the music rhythm. The activity starts with a slow run then it gradually goes faster until the sample cannot catch up the running rhythm time with the music rhythm.

\section{Treatment}

The frequency of training completed for 3 days in 6 weeks with the exercise intensity was $60-85 \%$ from each DNM and training time, which were 45 minutes; 10 minutes to warm up, 40 minutes to do the main activity, and 10 minutes to cool down. After that, the sample did a pretest to know the cardiorespiratory fitness score from both groups. Then, researchers led the sample to do aerobic dance training and water aerobics according to their group. Aerobics dance activities used for their lower body were single step, v step, double step, mambo, hicking, toe touch, jumping jack, double step diagonal, and jogging. For the upper body, the activities were butterfly, latenol noise, shoulder press, arm swing, biceps, chest, and pumping with 135-145 BPM songs.

For water aerobics movements, the upper body activities were shoulder horizontal flexion and extension, then elbow flexion and extension. Meanwhile for the lower body, hip flexion and extension then knee flexion and extension were done with 125-135 BPM songs. After that, researchers conducted a posttest to know the score of cardiorespiratory fitness after being given some treatments for each group. Lastly, researchers proceed the data to find out if there was a significant impact before and after implementing aerobics dance and water aerobics training. Researchers also compared both of them to find out if water aerobics was as effective as aerobic dance.

\section{E. Statistical Analysis}

Statistic analysis implemented in this research was the paired sample T-test based on the pretest and the posttest and independent sample T-test based on the gain score. Gain score was taken from the posttest score minus pretest score.

\section{RESULTS AND DISCUSSION}

According to the result of posttest with 20 samples divided into two groups, the data result is:

TABLE I. MEAN AND STANDARD DEVIATION FOR WATER AEROBICS AND AEROBIC DANCE

\begin{tabular}{|c|c|c|c|c|c|c|}
\hline \multirow[t]{2}{*}{ Group } & \multicolumn{2}{|c|}{ Pretest } & \multicolumn{2}{|c|}{ Posttest } & \multirow{2}{*}{$\begin{array}{c}\text { Paired } \\
\text { sample } \\
\text { t-test } \\
\text { (Sig) }\end{array}$} & \multirow{2}{*}{$\begin{array}{c}\text { Indepen } \\
\text { dent } \\
\text { Sample } \\
\text { t-test } \\
\text { (sig) }\end{array}$} \\
\hline & Mean & Stdev & Mean & Stdev & & \\
\hline $\begin{array}{c}\text { Water } \\
\text { aerobic }\end{array}$ & 37,87 & 1,76 & 38,78 & 1,76 & 0,000 & \multirow[t]{2}{*}{0,000} \\
\hline $\begin{array}{c}\text { Aerobics } \\
\text { dance }\end{array}$ & 39,61 & 1,75 & 41,02 & 1,88 & 0,000 & \\
\hline
\end{tabular}

Table 1 explained that the average of water aerobics group while doing the pretest was 37,87 with the standard deviation of 1,76 then after the water aerobics training program was given, the average changes to 38,78 with a standard deviation of 1,76 . Then, the average of aerobics dance group while doing the pretest is 39,61 with the standard deviation of 1,75 then after aerobics dance training program was given, the average changes to 41,02 with a standard deviation of 1,88 . Statistically, there is a difference between aerobics dance and water aerobics which states that to improve cardiorespiratory fitness, aerobics dance training program is more effective to boost cardiorespiratory fitness.

As stated above, cardiorespiratory fitness's boost may improve by doing sports with enough intensity, frequency, and duration, which the intensity that should be done to boost cardiorespiratory fitness is 50\%-85\% from DNM (Gaesser \& Rich, 1984, Burke \& Franks, 1975), with a frequency of 3 or 5 times a week [24] and with the duration of 15 - 25 minutes [23]. Thus, aerobics dance, as well as water aerobics, show a significant improvement to boost cardiorespiratory fitness. But the comparison explains that aerobics dance can be more effective than water aerobics, and it can be concluded that aerobic dance is more effective in boosting cardiorespiratory fitness rather than water aerobics.

Water aerobics is an existing kind of activity but not a lot of people aware of it. So, a lot of researchers have observed water aerobics. For example, research done by Chu et al. [25] used a water aerobics training program for 8 weeks and it significantly boosted physical fitness. The next research about water aerobics is by Grimm et al. [11] who did research using water aerobics for 7 weeks to women university students which followed a significant improvement in their cardiovascular fitness. But, research by Alegre et al. [26] stated that there was no change in aerobic capacity on the water aerobics training program for 24 weeks, which arises a doubt to the researchers. 
But, after researchers did the research, it can be concluded that water aerobics does improve cardiorespiratory fitness.

Aerobics dance is popular these days and a lot of people are already familiar with it. There are a lot of researches who observed the aerobic dance, one of them is Mehrtash et al. [27] who did research on aerobics dance to improve kids' motor ability and aerobic capacity for kids at the age of 10-13 and the result showed that there was a positive change in their motor ability. Helgerud et al. [28] stated that aerobics dance can boost aerobic capacity significantly. And Dowdy et al. [13] explained there was a significant result on VO2Max during aerobics dance training for 10 weeks. From some references showed above, all of them match with the result of this research that aerobics dance is proven to boost cardiorespiratory fitness (VO2Max).
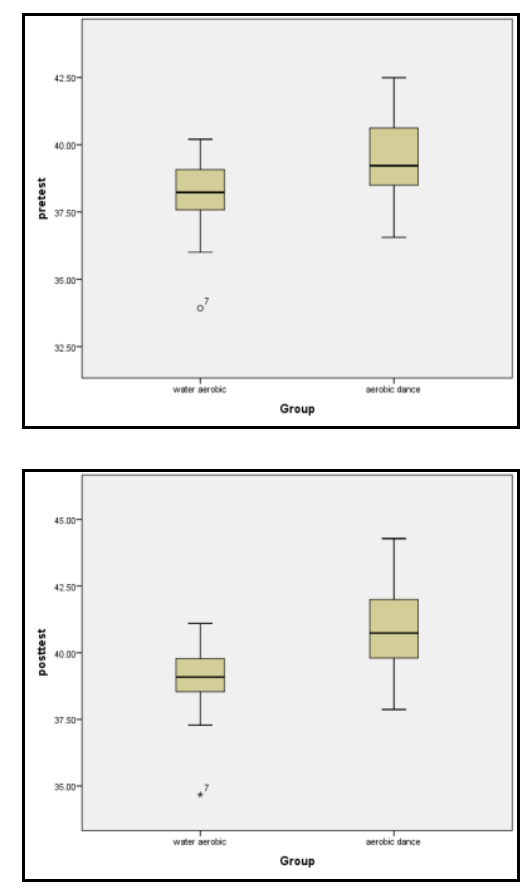

Fig. 1. Graphic data of pretest and posttest from water aerobics group dan aerobics dance group.

According to picture 1, water aerobics' pretest score is 37,78 and after treatment was implemented, it significantly boosted to 38,78 . During the pretest, aerobics dance has an average of 39,61 and it significantly boosted to 41,02 after training was given.

\section{CONCLUSIONS}

This research aims to find out about the impact of aerobics dance and water aerobics on improving cardiorespiratory fitness with 20 samples divided into two groups. The result of data analysis shows that physical activity like water aerobics and aerobics dance can be implemented to boost cardiorespiratory fitness because, from the output, there was a significant impact based on the pretest and posttest results of water aerobics and aerobics dance. The next conclusion found that there is a significant improvement on VO2Max for both groups where aerobics dance is more effective in improving cardiorespiratory fitness compared to water aerobics. Water aerobics can be implemented to boost VO2Max, but it is not as effective as aerobics dance.

\section{REFERENCES}

[1] U.S. Department of Health and Human Services, "Physical Activity and Health, Surgeon General Report," Natl. Cent. Chronic Dis. Prev. Heal. Promot., 1996.

[2] M. Kilpatrick, E. Hebert, and J. Bartholomew, "College students' motivation for physical activity: Differentiating men's and women's motives for sport participation and exercise," J. Am. Coll. Heal., vol. 54, no. 2, pp. 87-94, 2005.

[3] S.N. Blair, "61 Physical inactivity: the biggest public health problem of the 21st Century,” J. Sci. Med. Sport, vol. 10, p. 29, 2009.

[4] J.O.S.W.R. Twisk and H.A.N.C.G. Kemper, "Relationship With Cardiovascular Disease," Medicine (Baltimore), , no. 27, pp. 1455-1461.

[5] L. A. Kaminsky, W. Wayne, M. A. D, R. G. C, P. D. L, and M. H. Whaley, "Evaluation of a shallow water running test for the estimation of peak aerobic power." 1993.

[6] P. Rump, F. Verstappen, W.J.M. Gerver, and G. Hornstra, "Body Composition and Cardiorespiratory Fitness Indicators in Prepubescent Boys and Girls," vol. 2, 2002.

[7] W.W.K Hoeger and S.A. Hoeger, Lifetime Physical Fitness and Wellness: A Personalized Program, 11th Edition. Wadsworth, 2011.

[8] W.W.K. Hoeger and S.A. Hoeger, Jump-start your personal journey to health with Integrated with Hoeger and Hoeger' s text! Heads Up! If you have an access card your text, don' $t$ Log on to CengageNOW today! academic . cengage . com / cengagenow, Elizabeth. Wadsworth: Yolanda Cossio, 2009.

[9] M.F. Ahmad, M. Amir, and A. Rosli, "Effects of Aerobic Dance on Cardiovascular Level and Body Weight among Women," vol. 9, no. 12, pp. 874-882, 2015.

[10] B. Yuriy, P. Maryan, A. Sergiy, and V. Oleksandr, "Qualificational differences in the structure of archery training on different stages of Long-Term training," J. Phys. Educ. Sport, vol. 14, no. 3, pp. 426-430, 2014.

[11] W. Grimm, M. Christ, J. Bach, H. H. Müller, and B. Maisch, "The New England Journal of Medicine Downloaded from nejm.org at NCSU HUNT LIBRARY on May 27, 2014. For personal use only. No other uses without permission. From the NEJM Archive. Copyright (C) 2010 Massachusetts Medical Society. All rights reserved.," Circulation, vol. 108, no. 23, pp. 2883-2891, 2003.

[12] M.L. Pollock, H.S. Miller, R. Janeway, A. Linnerud, B. Robertson, and R. Valentino, "of middle-aged men," Appl. Physiol., vol. 3, pp. 126130, 2018.

[13] D.B. Dowdy, K.J. Cureton, H.P. Duval, and H.G. Ouzts, "Effects of aerobic dance on physical work capacity, cardiovascular function and body composition of middle-aged women," Res. Q. Exerc. Sport, vol. 56, no. 3, pp. 227-233, 1985.

[14] L.D. Williams and A.R. Morton, "Changes in selected cardiorespiratory responses to exercise and in body composition following a 12-week aerobic dance programme," J. Sports Sci., vol. 4, no. 3, pp. 189-199, 1986.

[15] M. Madhankumar, "AQUA AEROBIC EXERCISE AND AEROBIC EXERCISE RESPONSES ON VO2 MAX RESPONSE AMONG COLLEGE MEN STUDENTS : EFFECT STUDY," vol. 0, pp. 381382, 2017.

[16] T.J. Palekar, P.A. Shah, and M.R. Kadam, "Effect of Underwater Treadmill Training on Young Obese Adults," Int. J. Sci. Res. Sci. Technol., vol. 5, no. 4, pp. 1487-1492, 2018.

[17] A.B. Granath, M.S.E. Hellgren, and R.K. Gunnarsson, "Water aerobics reduces sick leave due to low back pain during pregnancy," JOGNN - J. Obstet. Gynecol. Neonatal Nurs., vol. 35, no. 4, pp. 465-471, 2006.

[18] M. Deanna Westby, "A health professional's guide to exercise prescription for people with arthritis: A review of aerobic fitness activities," Arthritis Rheum., vol. 45, no. 6, pp. 501-511, 2001. 
[24] H.A. Wenger and G.J. Bell, "The Interactions of Intensity, Frequency and Duration of," Sport. Med., vol. 3, no. 5, pp. 346-356, 1986.

[19] P.E. Calka, "EFFECTS OF A 24-WEEK DEEP WATER AEROBIC TRAINING PROGRAM ON,” vol. 27, no. 2, pp. 95-98, 2010.

[20] R.R. Costa et al., "Water-based aerobic training improves strength parameters and cardiorespiratory outcomes in elderly women," Exp. Gerontol., vol. 108, pp. 231-239, 2018.

[21] M.T. Mahar, A.M. Guerieri, M.S. Hanna, and C.D. Kemble, "Estimation of aerobic fitness from 20-m multistage shuttle run test performance," Am. J. Prev. Med., vol. 41, no. 4 SUPPL. 2, pp. S117-S123, 2011.

[22] G.A. Gaesser and R.G. Rich, "Effects of high-and low-intensity exercise training on aerobic capacity and blood lipids.," Med. Sci. Sports Exerc., vol. 16, no. 3, pp. 269-274, 1984.

[23] E.J. Burke and B.D. Franks, "Changes in VO2 max resulting from bicycle training at different intensities holding total mechanical work constant," Res. Quarterly. Am. Alliance Heal. Phys. Educ. Recreat., vol. 46, no. 1, pp. 31-37, 1975 .
[25] K.S. Chu, J.J. Eng, A.S. Dawson, J.E. Harris, A. Ozkaplan, and S. Gylfadóttir, "Water-based exercise for cardiovascular fitness in people with chronic stroke: A randomized controlled trial," Arch. Phys. Med. Rehabil., vol. 85, no. 6, pp. 870-874, 2004.

[26] P. Alegre, "MAXIMAL AND VENTILATORY THRESHOLDS OF OXYGEN UPTAKE AND RATING OF PERCEIVED EXERTION RESPONSES TO WATER AEROBIC EXERCISES,” vol. 27, no. 7, pp. 1897-1903, 2013.

[27] M. Mehrtash, H. Rohani, E. Farzaneh, and R. Nasiri, "The effects of 6 months specific aerobic gymnastic training on motor abilities in $10-12$ years old boys," Sci. Gymnast. J., vol. 7, no. 1, pp. 51-60, 2015.

[28] J. Helgerud et al., "Aerobic high-intensity intervals improve VंO2max more than moderate training," Med. Sci. Sports Exerc., vol. 39, no. 4, pp. 665-671, 2007. 